Supporting information for

\title{
Substrate-Photocaged Enzymatic Fluorogenic Probe Enabling Sequential Activation for Light-Controllable Monitoring of Intracellular Tyrosinase Activity
}

Sheng Yang, ${ }^{\dagger}, \S$ Jiaxing Jiang, ${ }^{\dagger, \S}$ Anxin Zhou, ${ }^{\dagger, \S}$ Yibo Zhou, ${ }^{\dagger}$ Wenling Ye, ${ }^{\ddagger}$ Dong-Sheng Cao, ${ }^{\ddagger}$ and Ronghua Yang ${ }^{\dagger *}$

${ }^{\dagger}$ Hunan Provincial Key Laboratory of Cytochemistry, School of Chemistry and Food Engineering, Changsha University of Science and Technology, Changsha, 410114, P. R. China

¿School of Pharmaceutical Sciences, Central South University, Changsha 410003, P.R. China

$\S$ These authors contributed equally to this work.

*To whom correspondence should be addressed:

E-mail: yangrh@pku.edu.cn 


\section{Table of Contents}

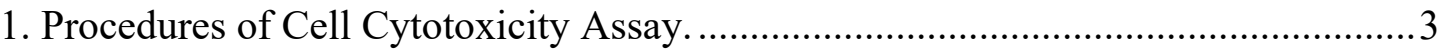

2. Studies on Reaction Mechanism ........................................................................... 4

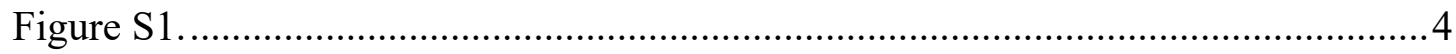

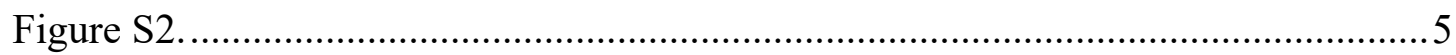

3. Optimization of Experimental Conditions ............................................................ 5

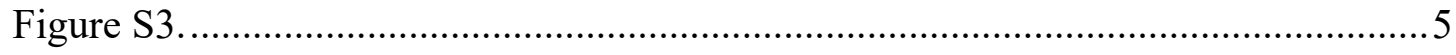

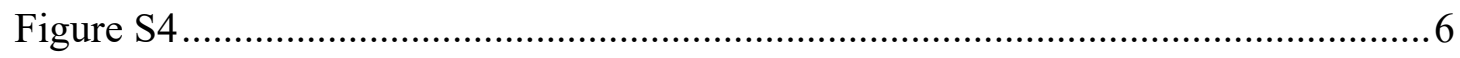

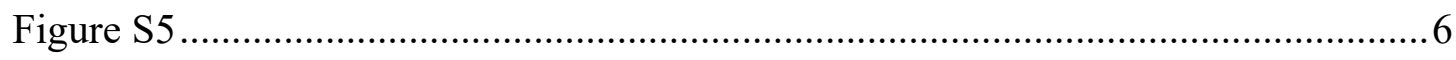

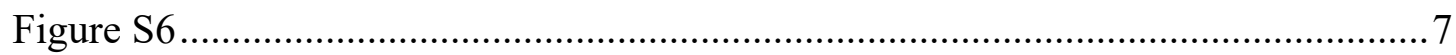

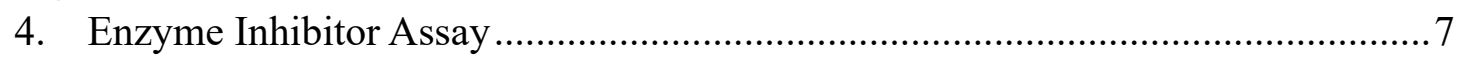

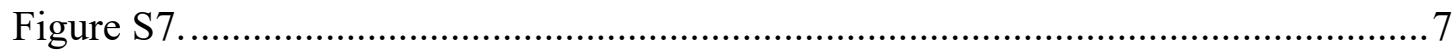

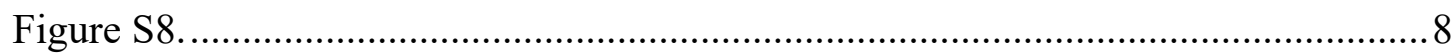

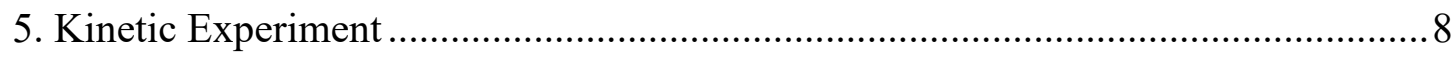

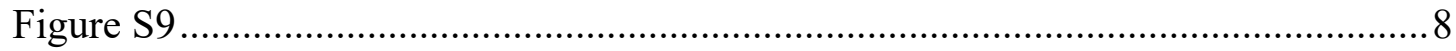

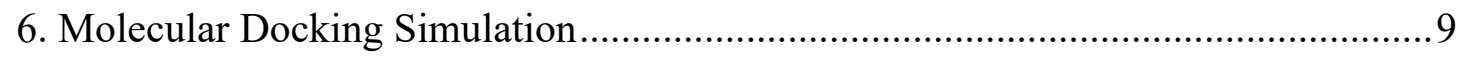

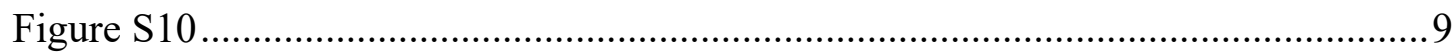

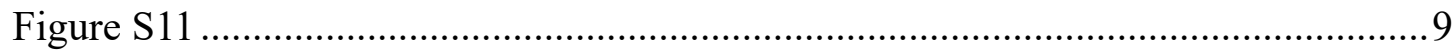

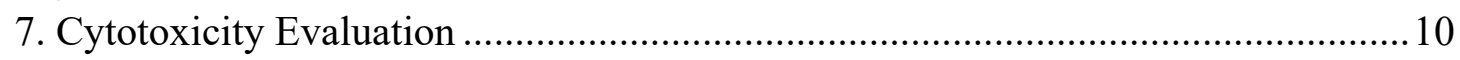

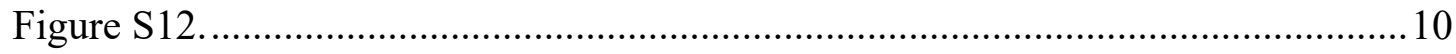

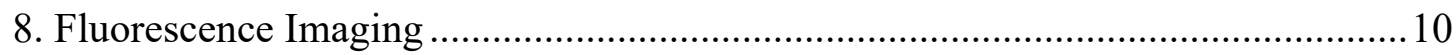

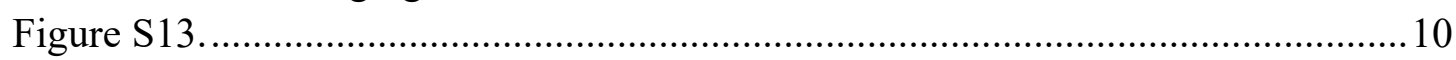

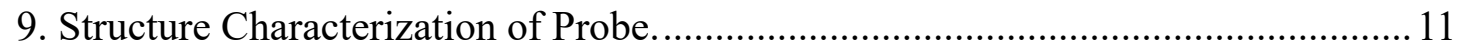

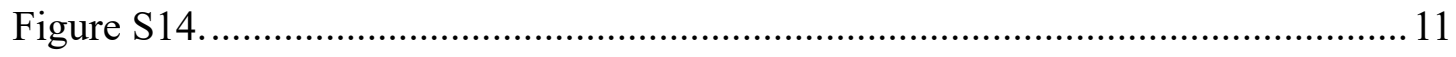

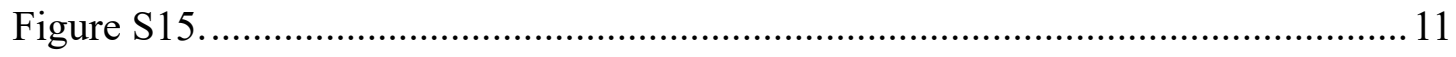

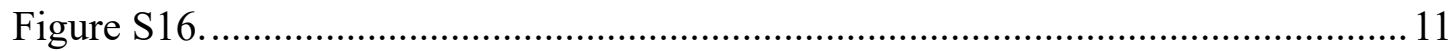




\section{Procedures of Cell Cytotoxicity Assay.}

The cellular cytotoxicity of PTFP towards B16 cells as the model was evaluated using the standard MTT assay. B16 cells were seeded into a 96-well plate at a concentration of $5 \times 10^{3}$ cells well-1 in $100 \mu \mathrm{L}$ of DMEM medium with $10 \%$ NBCS. Plates were maintained at $37{ }^{\circ} \mathrm{C}$ in a $5 \% \mathrm{CO}_{2} 95 \%$ air incubator for $24 \mathrm{~h}$. After the original medium was removed, the B16 cells were incubated with different concentrations of PTFP $(0-25 \mu \mathrm{M})$ for $12 \mathrm{~h}$. The cells incubated with the culture medium only were served as the controls. The cells were washed with PBS for three times and then $10 \mu \mathrm{L}$ MTT solution $\left(0.5 \mathrm{mg} \mathrm{mL}^{-1}\right.$ in PBS) was added to each well. After addition of DMSO $\left(100 \mu \mathrm{L}\right.$ well $\left.{ }^{-1}\right)$, the assay plate was allowed to shake at room temperature for $10 \mathrm{~min}$. The spectrophotometrical absorbance of the samples was measured by using a microplate reader VersaMax. The cell viability was calculated based on measuring the UV-vis absorption at $570 \mathrm{~nm}$ using the following equation, where $\mathrm{OD}_{570}$ represents the optical density.

$$
\text { Cell viability }=\left[\mathrm{OD}_{570(\text { sample })}-\mathrm{OD}_{570(\text { blank })}\right] /\left[\mathrm{OD}_{570(\text { control })}-\mathrm{OD}_{570(\text { blank })}\right]
$$




\section{Studies on Reaction Mechanism}

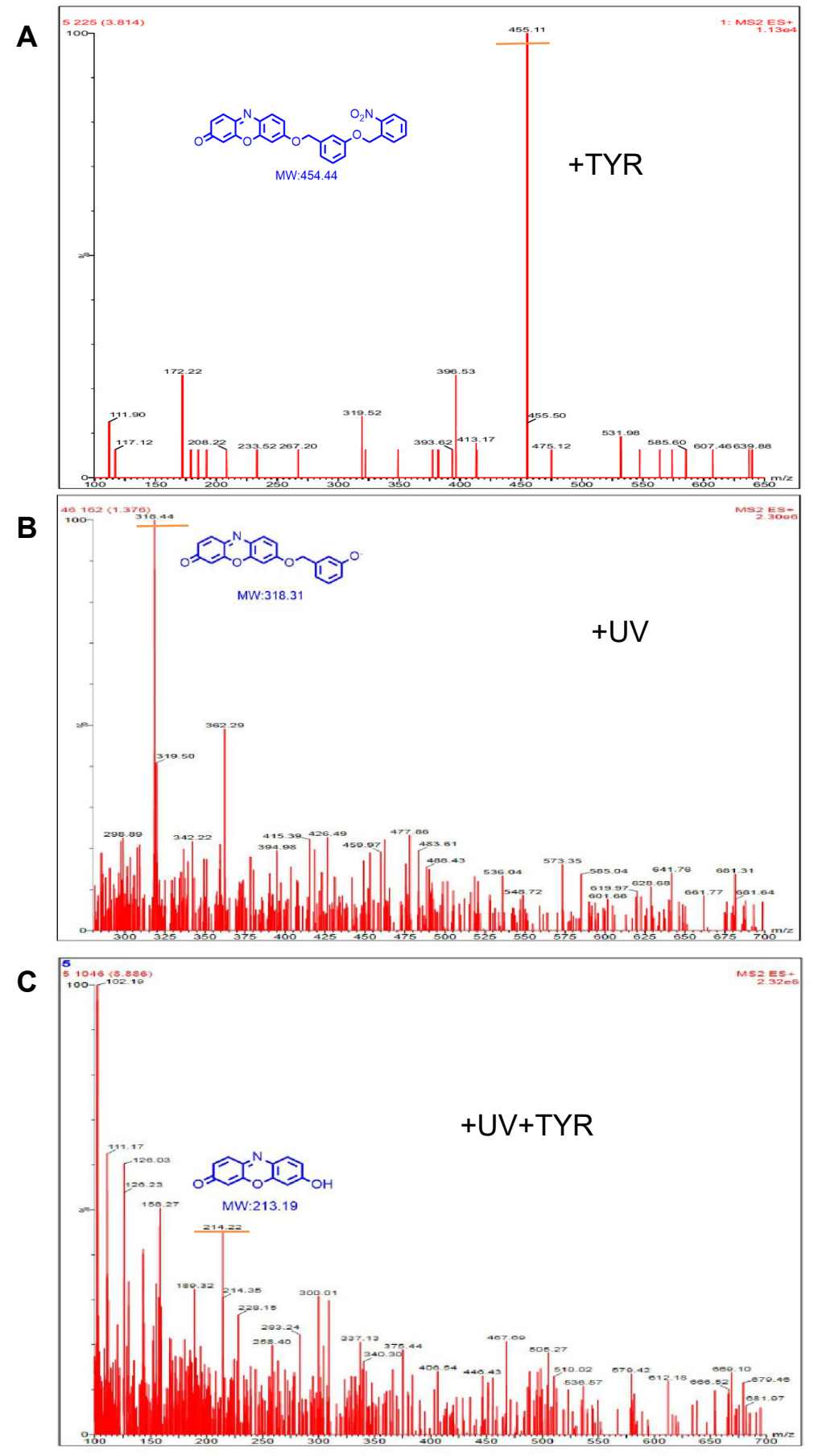

Figure S1. (A) Mass spectrum of the reaction solution of PTFP $(200 \mu \mathrm{M})$ with TYR (400 U/mL). (B) Mass spectrum of the reaction solution of PTFP $(200 \mu \mathrm{M})$ with exposure to the UV light $(365 \mathrm{~nm})$. (C) Mass spectrum of the reaction solution of PTFP $(200 \mu \mathrm{M})$ with exposure to the UV light $(365 \mathrm{~nm})$ in the presence of TYR (400 
$\mathrm{U} / \mathrm{mL})$.

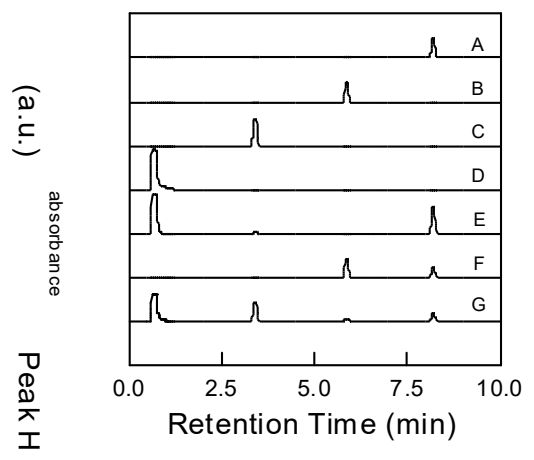

Figure S2. Chromatograms of different reaction systems. (A) PTFP $(200 \mu \mathrm{M})$; (B) CP $(200 \mu \mathrm{M})$; (C) resorufin $(200 \mu \mathrm{M})$; (D) TYR(400 U/mL); (E) the solution of PTFP $(200 \mu \mathrm{M})$ treated with $400 \mathrm{U} / \mathrm{mL}$ TYR for $3 \mathrm{~h}$; (F) the solution of probe PTFP (200 $\mu \mathrm{M})$ after exposure to UV light $(365 \mathrm{~nm}) ;(\mathrm{G})$ the solution of probe PTFP $(200 \mu \mathrm{M})$ after exposure to UV light $(365 \mathrm{~nm})$ with $400 \mathrm{U} / \mathrm{mL}$ tyrosinase for $3 \mathrm{~h}$. The assignments of the peaks: (1) $0.67 \mathrm{~min}$, tyrosinase; (2) $3.41 \mathrm{~min}$, resorufin; (3) 5.87 min, CP; (2) $8.21 \mathrm{~min}$, PTFP. The peaks eluted from the column were monitored at $254 \mathrm{~nm}$ with methanol and water as eluents.

\section{Optimization of Experimental Conditions}

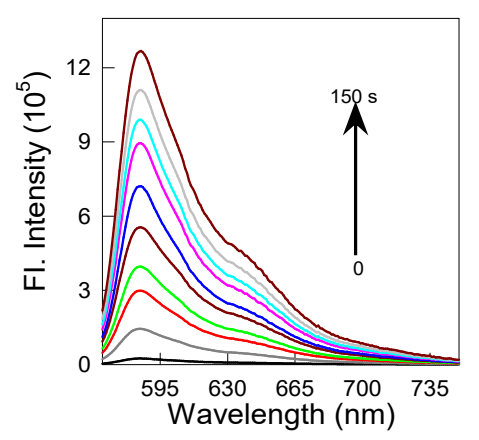

Figure S3. Fluorescence emission spectra of PTFP $(100 \mathrm{nM})$ in the presence of TYR $(190 \mathrm{U} / \mathrm{mL})$ after $\mathrm{UV}$ illumination for various periods $(0-150 \mathrm{~s}) . \lambda_{\mathrm{ex} / \mathrm{em}}=550 / 586 \mathrm{~nm}$. 


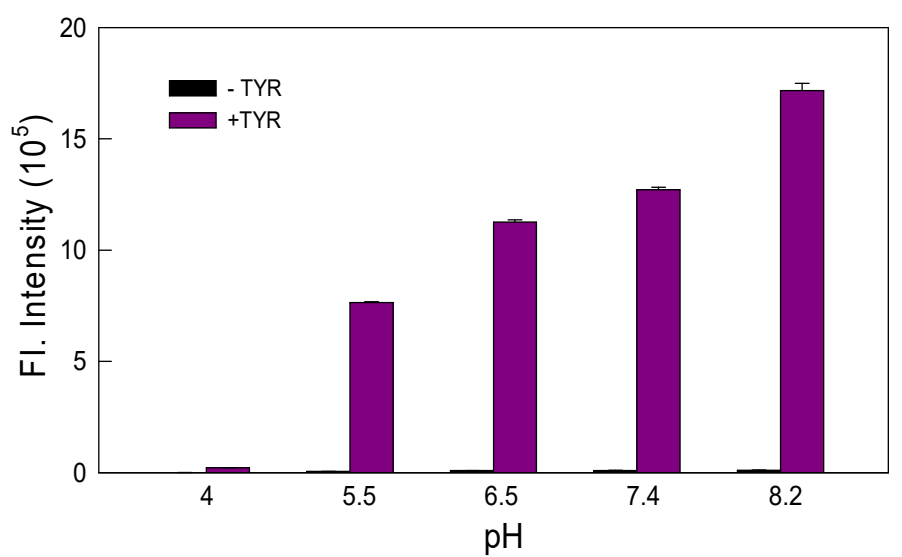

Figure S4. Effects of $\mathrm{pH}$ on the fluorescence intensity of PTFP $(100 \mathrm{nM})$ after exposure to UV light $(365 \mathrm{~nm})$ in the absence or presence of TYR $(190 \mathrm{U} / \mathrm{mL})$. The measurements were performed at $37^{\circ} \mathrm{C}$ with $\lambda_{\mathrm{ex} / \mathrm{em}}=550 / 586 \mathrm{~nm}$. The results are expressed as the mean \pm standard deviation of three separate measurements.

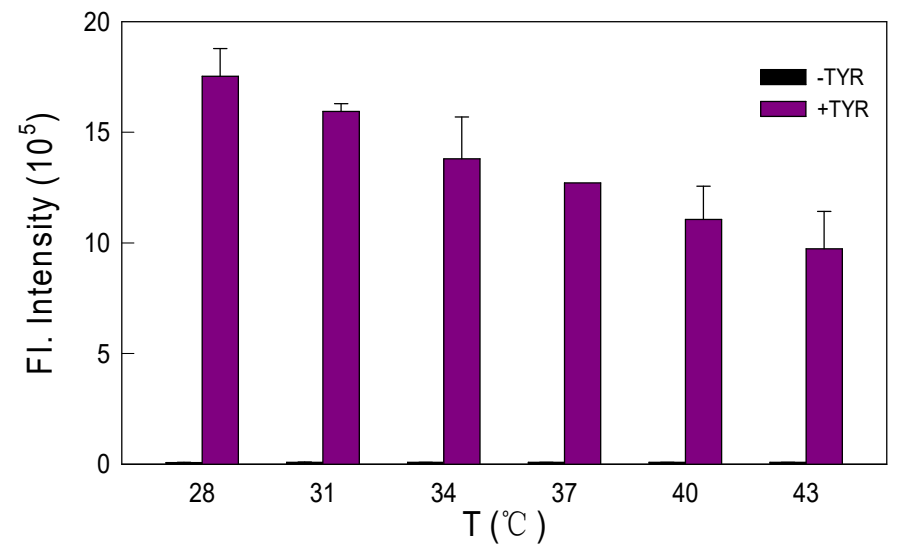

Figure S5. Effects of temperature on the fluorescence intensity of PTFP (100 nM) after exposure to UV light $(365 \mathrm{~nm})$ in the absence or presence of TYR $(190 \mathrm{U} / \mathrm{mL})$. The measurements were performed at $\mathrm{pH} 7.4$ with $\lambda_{\mathrm{ex} / \mathrm{em}}=550 / 586 \mathrm{~nm}$. The results are expressed as the mean standard deviation of three separate measurements. 


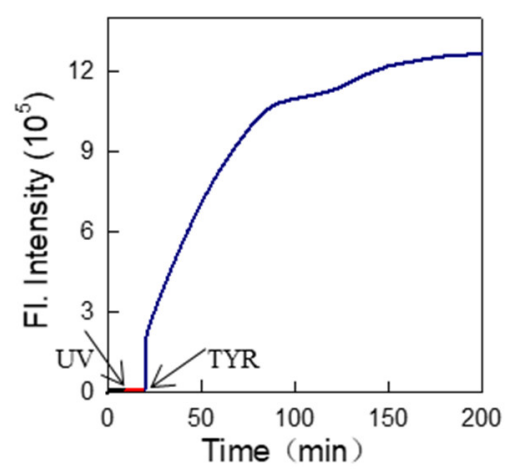

Figure S6. Real-time fluorescence intensity records of $100 \mathrm{nM}$ PTFP (black line) and it irradiated with UV light (red line), following addition of $190 \mathrm{U} \backslash \mathrm{mL}$ TYR (blue line). The transition between each regime is marked with an arrow.

\section{Enzyme Inhibitor Assay}

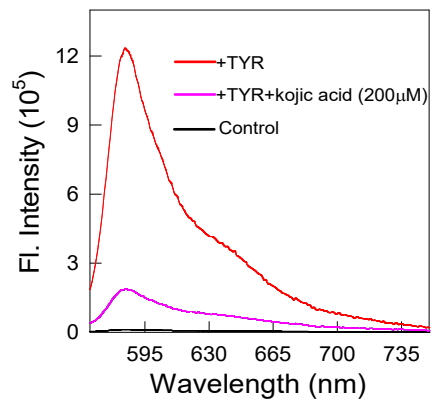

Figure S7. Fluorescence intensity of different reaction systems: (A) 100 nM PTFP exposure to UV light (black line); (B) system (A) + tyrosinase (190 U/mL) (red line); (C) system (B) + kojic acid $(200 \mu \mathrm{M})($ pink line $) . \lambda \mathrm{ex} / \mathrm{em}=550 / 586 \mathrm{~nm}$. 


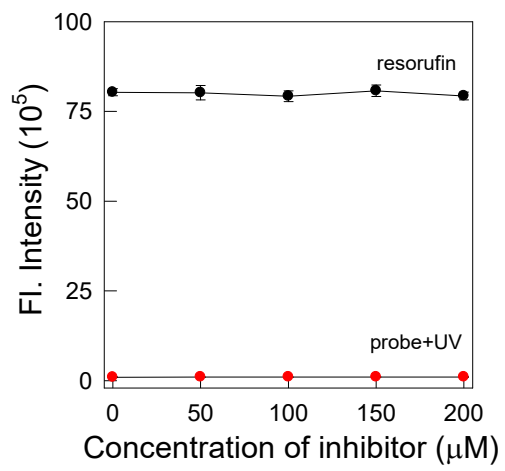

Figure S8. Effects of inhibitor with different concentrations (0, 50, 100, 150, and 200 $\mu \mathrm{M})$ on the fluorescence $(\lambda \mathrm{ex} / \mathrm{em}=550 / 586 \mathrm{~nm})$ of resorufin and PTFP exposure to UV light. The results are the mean \pm standard deviation of three separate measurements.

\section{Kinetic Experiment}

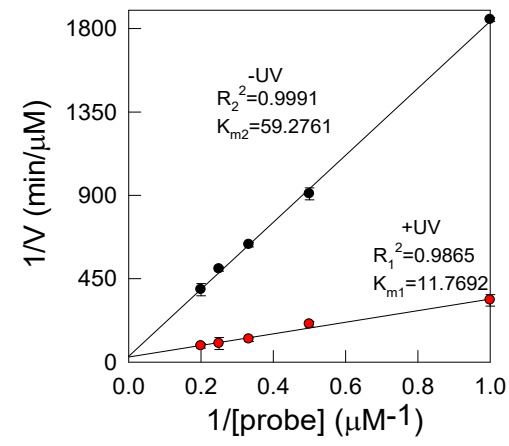

Figure S9. Lineweaver-Burk plot for the TYR-catalyzed reactions of PTFP with and without and with exposure to UV light. The Michaelis-Menten equation was described as: $\mathrm{V}=\mathrm{V}_{\max }$ [probe] $/\left(\mathrm{K}_{\mathrm{m}}+\right.$ [probe]), where $\mathrm{V}$ is the reaction rate, [probe] is the probe concentration, and $\mathrm{K}_{\mathrm{m}}$ is the Michaelis constant. Conditions: $50 \mathrm{U} / \mathrm{mL}$ TYR, 1-5 $\mu \mathrm{M}$ of probe without and with exposure to UV light. The measurements were performed at $37^{\circ} \mathrm{C}$ with $\lambda_{\text {ex } / \mathrm{em}}=550 / 586 \mathrm{~nm}$. 


\section{Molecular Docking Simulation}

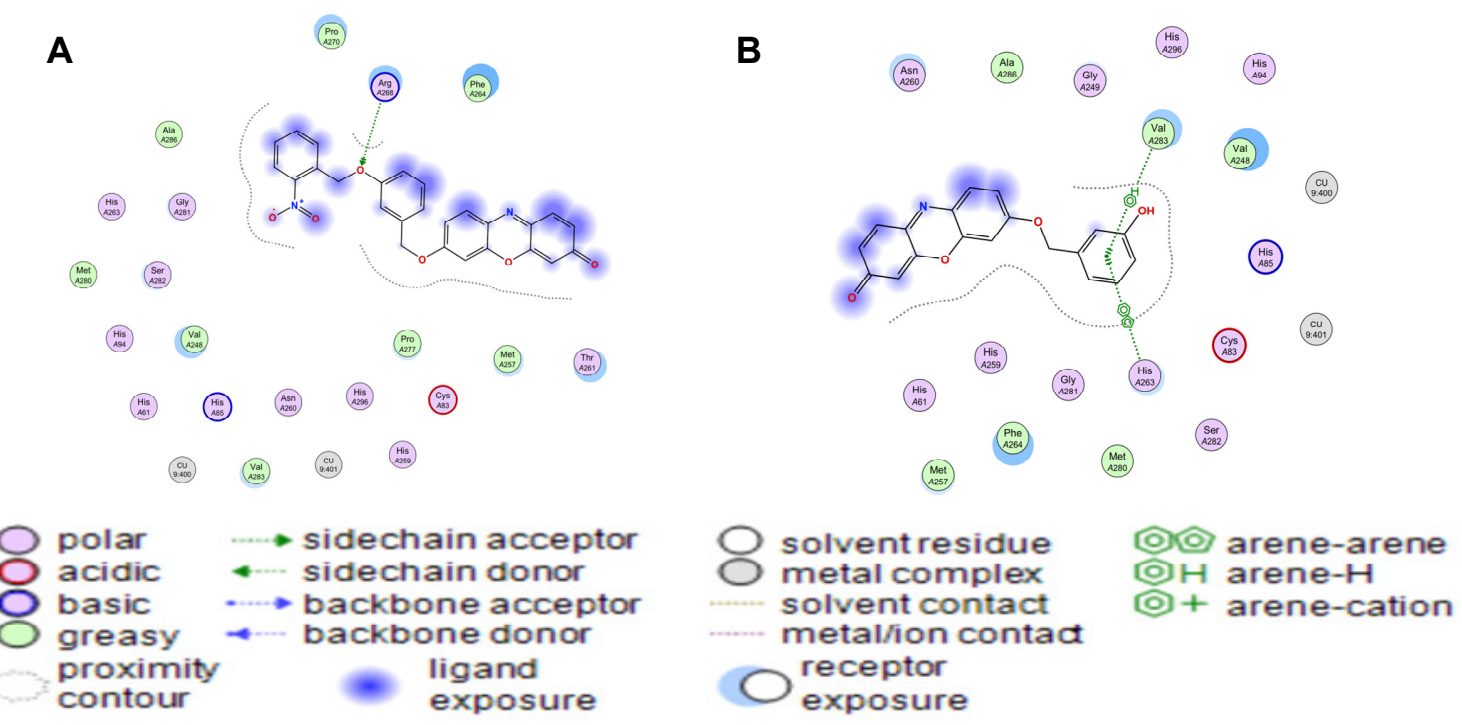

Figure S10. 2D binding mode of (A) the caged probe PTFP and (B) control probe CP

to tyrosinase active site.
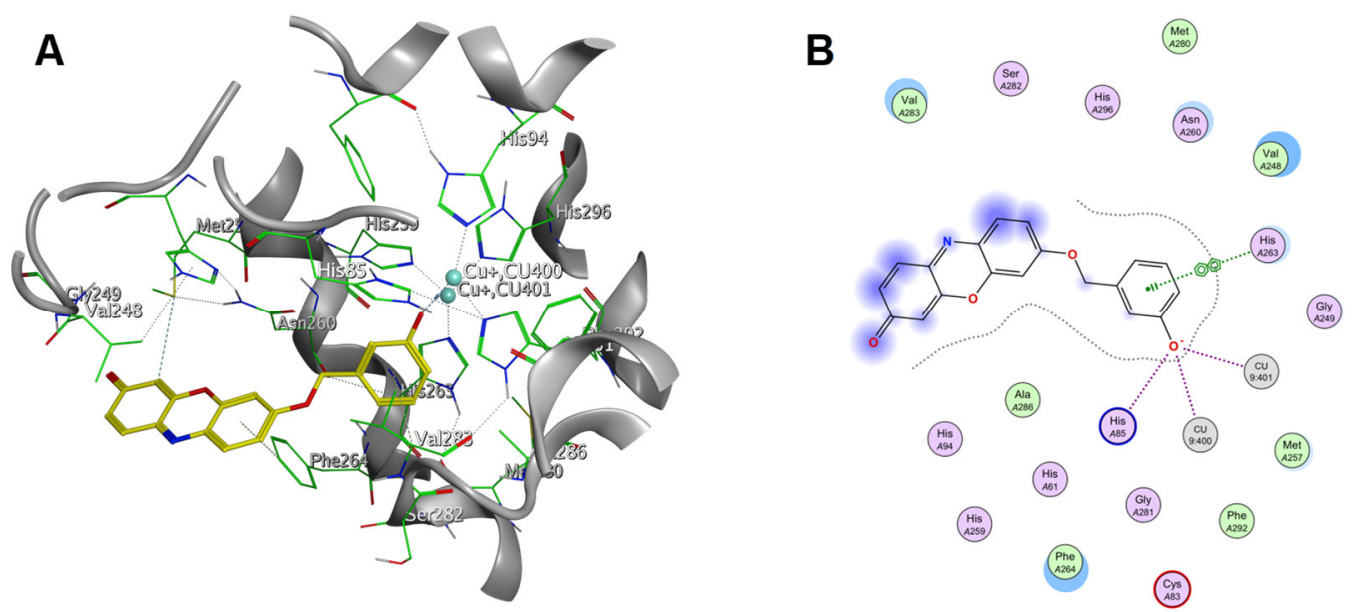

Figure S11. 3D (A) and 2D (B) binding mode of the deprotonated control probe $\mathbf{C P}$ to tyrosinase active site. 


\section{Cytotoxicity Evaluation}

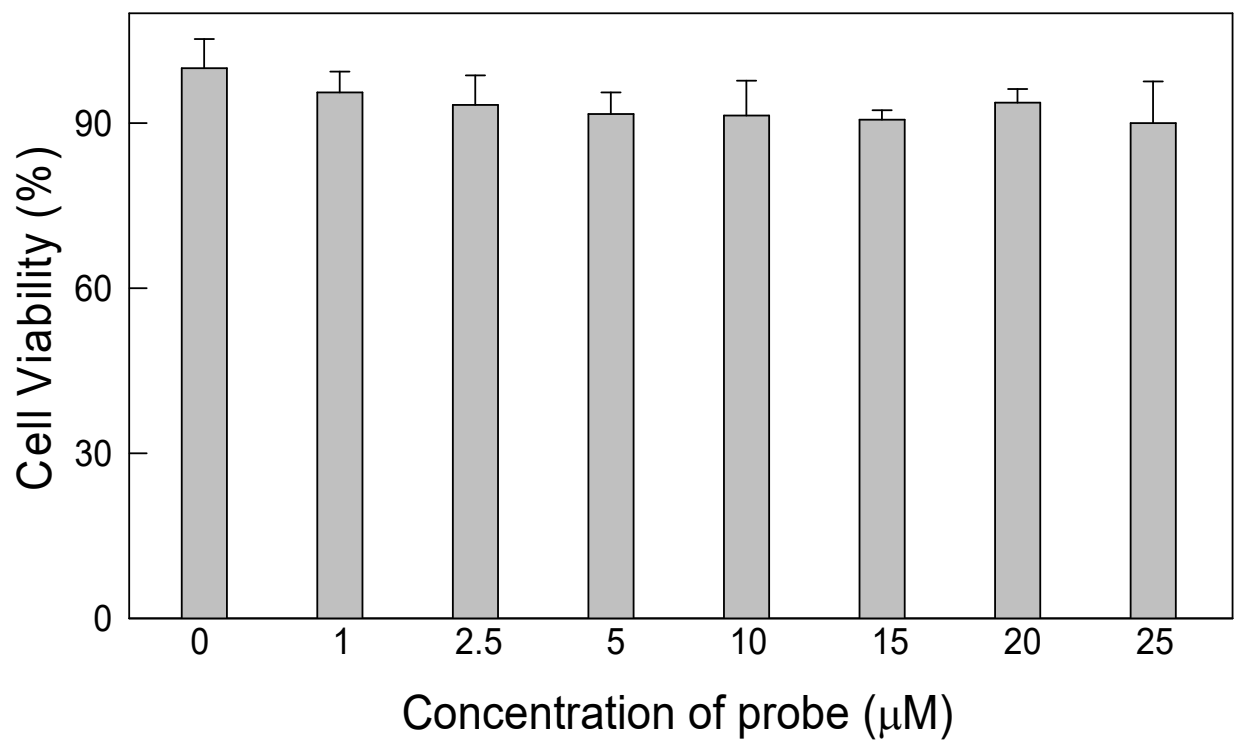

Figure S12. Effects of PTFP at varied concentrations $(0-25 \mu \mathrm{M})$ on the viability of cells. The viability of the cells without probe is defined as $100 \%$. The results are expressed as the mean \pm standard deviation of three separate measurements.

\section{Fluorescence Imaging}
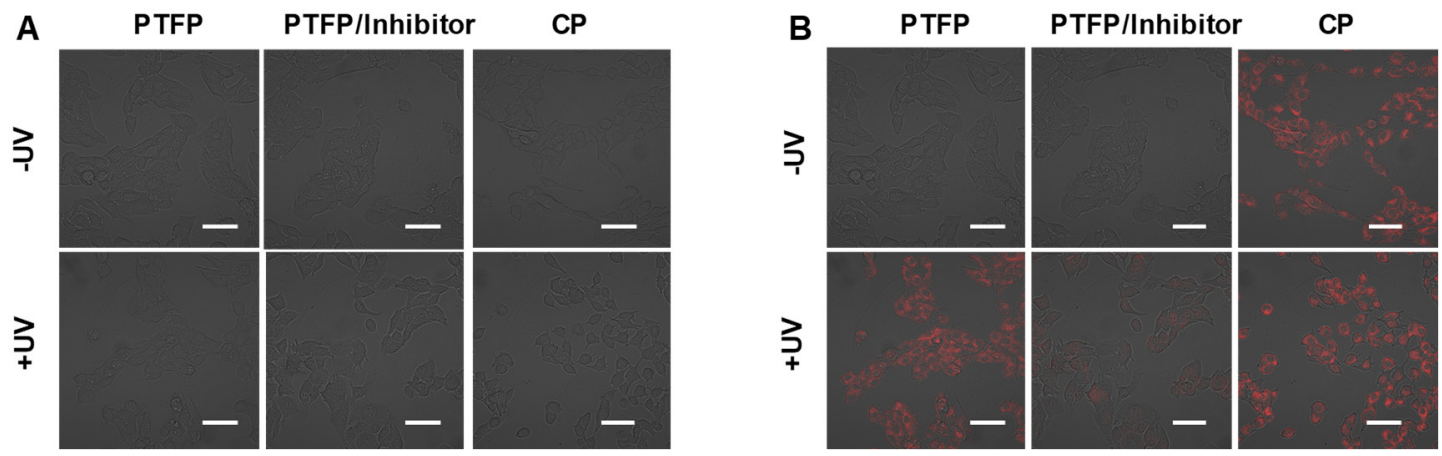

Figure S13. Bright field (A) and Merge (B) of B16 cells using caged or control probe without (upper) and with (down) exposure to UV light under different conditions: (left) incubation with PTFP $(5 \mu \mathrm{M})$; (middle) incubation with PTFP $(5 \mu \mathrm{M})$ in the presence of kojic acid $(200 \mu \mathrm{M})$; (right) incubation with $\mathbf{C P}(5 \mu \mathrm{M})$. Scale bar: 50 $\mu \mathrm{m}$. 
9. Structure Characterization of Probe.

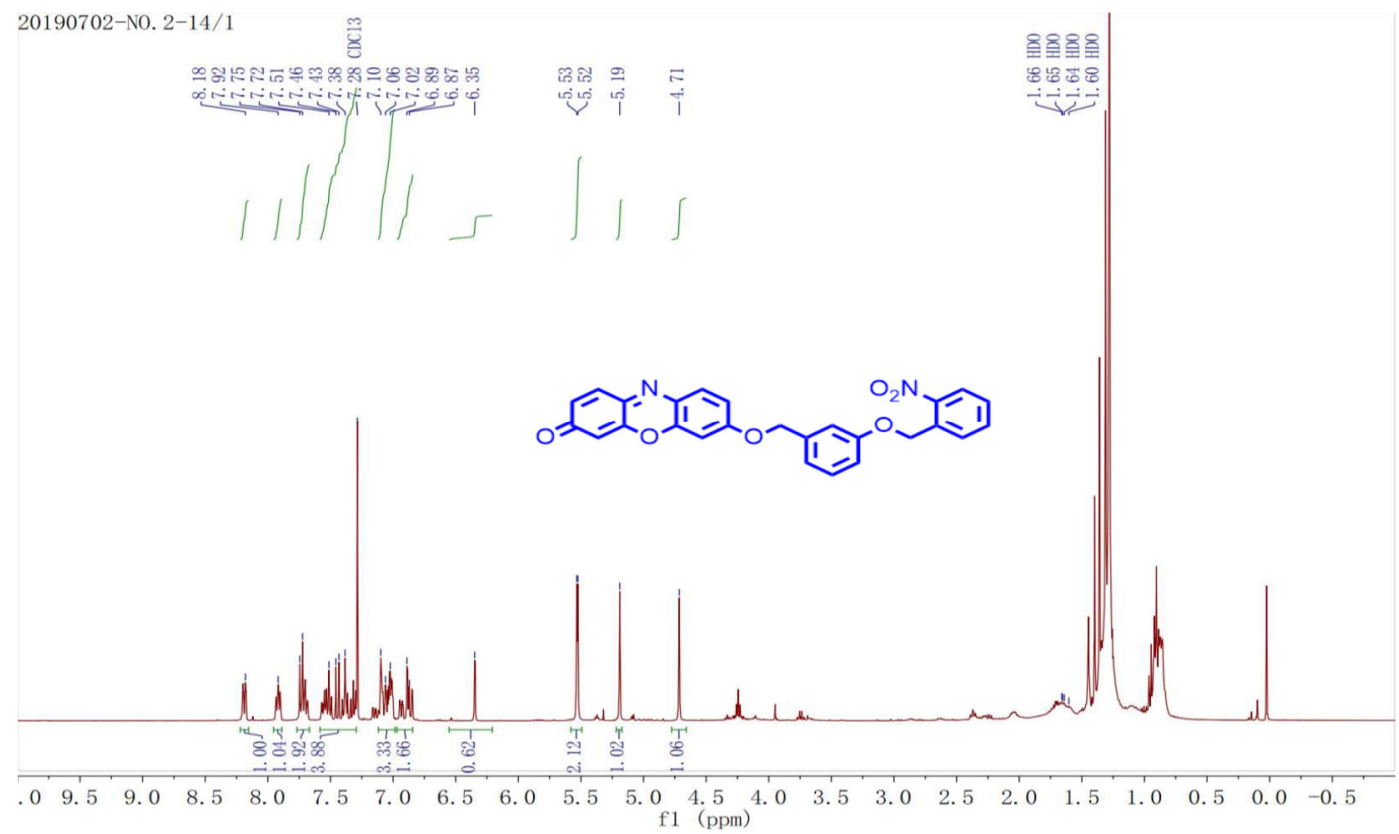

Figure S14. ${ }^{1} \mathrm{H}$ NMR of PTFP in $\mathrm{CDCl}_{3}$

20190702-N0. 2-14/2

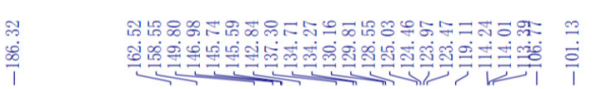
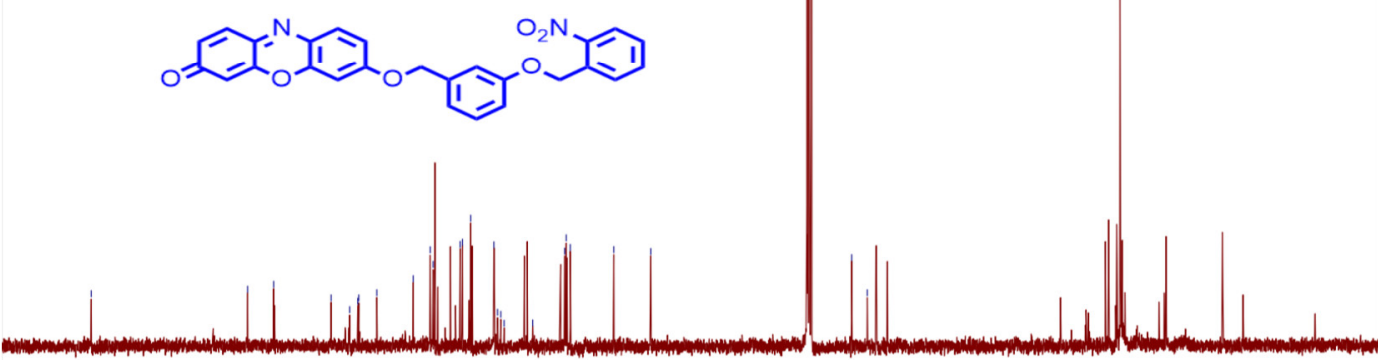

\begin{tabular}{llllllllllllllllllllllllll}
\hline 10 & 190 & 180 & 170 & 160 & 150 & 140 & 130 & 120 & 110 & 100 & 90 & 80 & 70 & 60 & 50 & 40 & 30 & 20 & 10 & 0 & -
\end{tabular}

Figure S15. ${ }^{13} \mathrm{C}$ NMR of PTFP in $\mathrm{CDCl}_{3}$ 


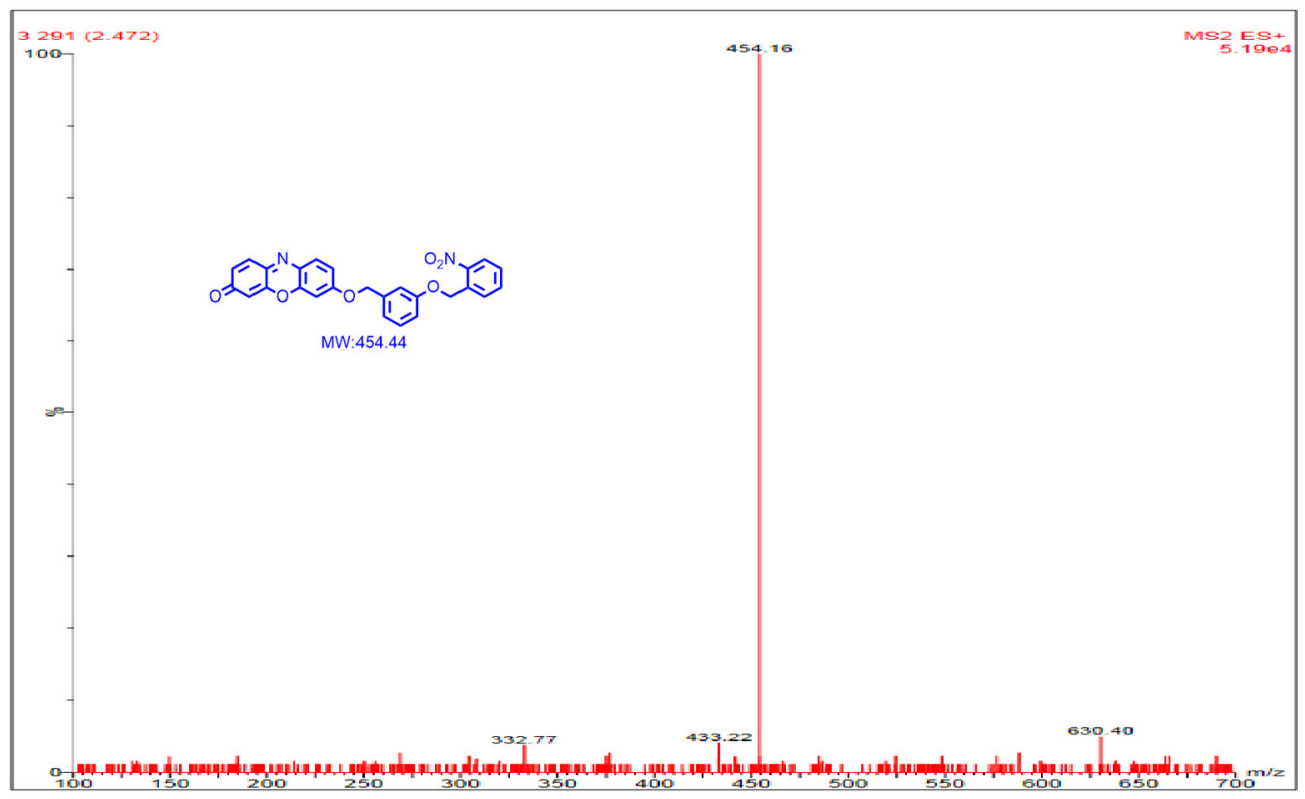

Figure S16. ESI-MS of PTFP 